\title{
Casting Design with Help of Information Fusion
}

\author{
Sylke Krötzsch ${ }^{1}$, Ines Hofmann ${ }^{2}$, Georg Paul ${ }^{1}$ \\ ${ }^{1}$ Institute of Technical and Business Information Systems, Otto-von-Guericke-University \\ Magdeburg, Universitätsplatz 2, 39106 Magdeburg, Germany \\ ${ }^{2}$ Institute of Manufacturing Technology and Quality Management Otto-von-Guericke- \\ University Magdeburg, Universitätsplatz 2, 39106 Magdeburg, Germany
}

\begin{abstract}
The computer aided support of several tasks is the main focus in a lot of companies. Especially the work scheduling and the casting design in foundries is an important area which is responsible for the economical survival on the world market. This paper contains proposals for a better support of the phases of the work scheduling and the casting design with help of modern computer techniques. At first a review of the research group "Information Fusion" is given. Thereafter several aspects of the work scheduling are explained, like the integrated process of the workout of offers and scheduling of the manufacturing, the in- and outgoing conditions at the workout of offers, checklists and databases for technical checks etc. In order to manage this mentioned main points of the work scheduling, a Control-System, like Workflow Management Systems, is introduced. The paper presents various solutions in order to support the workout of offers.
\end{abstract}

\section{Keywords}

Computer Aided Engineering, Offers for Castings, Information Fusion, Workflow Management

\section{Introduction}

Technologies, like information processing and communication, are currently developed very quickly worldwide. The casting industry (e.g. automobile industry or machine building industry) uses the new developments with big success. Examples are CADSystems for casting construction and systems for stress and solidification simulations $[1,2]$. The $50 \%$ quota of CAD-data in die casting plants is much higher than in steel and iron foundries. Here a quota of $10 \%$ was ascertained [3,4]. An analyse of the development in foundries results in the fact, that there is no complex system which is able to integrate progressive technologies for information processing and communication oriented on requirements of the casting industry. In order to ensure a permanent coexistence of the casting industry in ensemble with the most efficient machine-building and equipmentbuilding industry, an adaption to the progressive developments is necessary. The continuous use of the information and communication technology in all sections of foundries is the future goal. In order to achieve the goal, a scientific penetration of the company own technological process is necessary.

Presently one mainpoint of the DFG-Research Group "Workbench for Information Fusion" is the casting design process.

\section{Information Fusion and Work Scheduling}

The research group "Workbench for Information Fusion" combines the work of several part projects, in order to develop new techniques, concepts and methods for produce information in a better quality. There are six part projects which develop concepts for the workbench. Another three part projects establish the applicaion areas. "Casting Technoloy" is one application field, which analyzes the casting design process with the aim to get information in a new quality with new concepts and techniques of computer science. Here some databases with foundry specific data and other auxiliary means are used. During the processes of work scheduling the staff used the available databases directly. That means the employee get only the stored information of a specific database. With help of the concepts and techniques of the workbench it is tryed to get information in a new high quality. This is possible because all databases are used for decision making and the workbench filter the relevant information for specific tasks. An overview of the "Workbench of Information Fusion" is given in fig. 1. The application profile "Casting Technology" works with a lot of different data. For instance, normal documents (e.g. norms and pictures), CAD-Data, and different databases are used during the casting design process.

These data support the decisions of the employee during the single worksteps. The data are distributed in heterogenous databases, technical manuals, or as expert knowledge. Especially the last point is a very important fact in the casting design process. The expert knowledge is available in a fuzzy kind and it is very difficult to prepare the knowlegde for a computer aided processing. Almost the complete knowledge of a company is normally combined at the 
work scheduling (in extreme manner). For instance, information to economical questions, questions about material, logistic, operations, and equipment, as well as questions to the quality assurance, qualifications of the worker, and so on are accumulate in foundries.

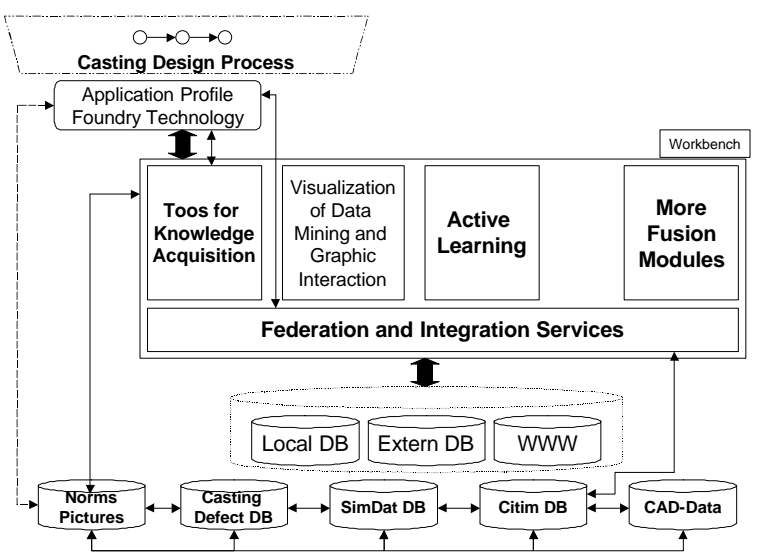

Fig. 1: Workbench for Information Fusion

An important part of the casting design process is the work scheduling in foundries. Already here the first decisions about the casting are made. Normally the work scheduling is executed in two steps. The process begins with Phase 2 (fig. 2), the workout of an exact offer, after an inquiry by a customer is received. In case of getting an order by the customer Phase 3 (fig. 2), the elaboration of the work documents, is executed. The steps of workout of offers and elaboration of work documents differ from each other in the level of detail. In context of the casting design process the work scheduling is expanded. This means, there is one phase more (Phase 1), the workout of a rough offer. Fig. 2 shows the necessary work steps and clarifies the connection between the first two phases. The new strategy starts with Phase 1 (fig. 2), if the foundry would like participate in the product development process together with the customer. The decision must be deliberate by the foundry because the product development needs time and causes costs. But on this way the company tryed to get a good basic position in order to get the order. The rough offer comprehends the necessary product development information for a specific casting. If the foundry get the offer for product development an exact offer is create (Phase 2). The main focus is the cooperation with the customer during the casting design process. On this way it is possible to consider all necessary requirements for casting technical view. Phase 3 is uncoupled from the workout of offers.

The practical experiences of the executed analyses in range of expedient Workflow Management Systems in foundries confirm the necessary insert of new techniques $[5,8]$. Both reliable company-intern (e.g. information flows between workout of offer, marketing, and manufacturing) and company-extern (e.g. information flows between engineering offices, customer, cooperation partner, etc.) information flows are required, which are supported and warranted by adequate multimedia techniques [6]. The goal of information processing systems is the storage and processing of different types of information in only one system, like acoustic and visual information. This is required because the quantity and quality of information is relates to permanently changes by the simultaneous cooccurrence of heterogeneous information. Furthermore a use of these information at any time by planning engineers and by other competent employees is required.

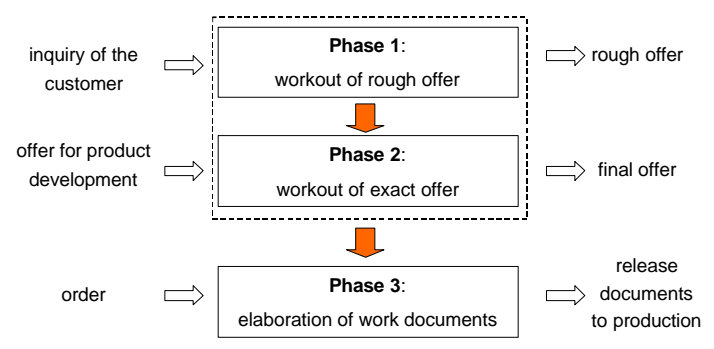

Fig. 2: Phases of Work Scheduling in Foundries

Such new approach requires a demanding data management [7] and a high qualification and discipline oriented on the warranty of the actuality of data. All modifications have to be gathered and stored consequently by authorized staff. The major hurdle on this way is the insufficient scientific penetration of the technological processes in foundries (e.g. the control of the cavity fill process, in particular on complicated castings) and the economic evaluation (e.g. ascertainment of the limits of economic manufacturing with available resources). In the following the main results of the analyses of work scheduling in foundries are introduced. They are oriented on contents of the research project "Casting Technology“.

\section{Reference Processes of the Work Scheduling}

The precondition to a successfull existence of a company on the world market are qualified offers, which are elaborated in a short term. Interviews in foundries results in an increasing number of delivered offers in the last years $(35 \%)$. In the same time the success rate came under $30 \%$. The main worksteps for workout of offers are "register the inquiry", "test and rate the inquiry", "set pre-definitions", "calculate inquiry", "calculate extern inquiry" and "create 
offer". These steps are executed more or less detailled in the companies dependent on inquiry valence and the type of customer [13]. In case of small inquiry volume no generation of a raw product is executed and the data of similar calculation documents are used. These documents are sorted in similar and already produced castings. In foundries auxiliary means for the workout of offers are used, like guiding principles, standards, several methods for checking the manufacturing oriented design, nomograms, casting classifications, regression equations for ascertainment of allowed times, material sheets and so on. Very often offers of already produced castings are used, which are stored in file form or they are managed in specific production planning and control systems which are based on concepts like Material Resource Planning (MRP I) and Manufacturing Resource Planning (MRP II). In order to support the work scheduling, at the Otto-von-Guericke-University Magdeburg in collaboration with a well-known foundry a concept for an efficient computer-aided solution was developed [8].

The analyses during the research project contains the development of auxiliary means [8, 11]. These are checklists for completeness check and verification of offers, the database "check the producibility of inquiries", and the algorithm for "generation the raw product". These components are introduced in the following.

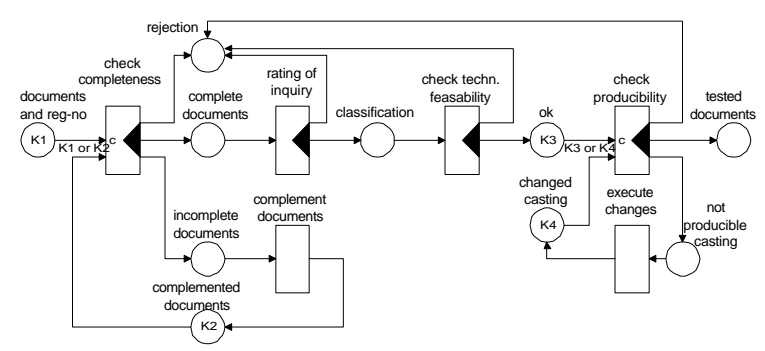

Fig. 3: Subsequence "test and rate the inquiry"

The process step "test and rate the inquiry" is subdivided in a subsequence (fig. 3). In order to model the identified process steps FunSoft-Nets are used [12]. Here all necessary steps for testing the inquiry are executed. The workout of offers starts normally with a completeness check of the inquiry documents. In order to represent the efficiency and the service of the foundry, the goal is the reduction of consultations with the customer. In collaboration with a well-known foundry a checklist was developed which completes missing information in dialogue with the employee.

The missing information are to differ in necessary and desired characteristics. Necessary characteristics influence the technology of castings, the manufacturing costs, and the quality. An elaboration of desired characteristics with help of necessary characteristics is possible. In the following an example is introduced. The manufacturing means for casting production (manual or automated) depends on the piece number. Is the piece number not specified by the customer (5\% of the inquiries) the foundry submit an alternative offer, provided that several mechanized and automated form plans are available in the foundry. The proposal of automated mold plants is dependent on the minimal economic piece number (manual mold $=$ piece number of 1 ). Not in each case the foundry elaborate an offer. It is also possible to eliminate an inquiry before the process step "check completeness" is executed. Reasons for this can be a desiderative reliability of the customer, a small volume of trade, a small piece number (e.g. a new production line for the product is not advisable), and a cognizable compare of inquiries (e.g. the customer gets normally his products from another supplier).

Another very important point during the workout of offers is the weighting of the inquiries. In the context of the research group "Workbench for Information Fusion" a rule-based program is developed, which is adapted for a weighting of the inquiries in foundries. With help of the checklist several points were testet. Based on the tests the inquiry will evaluated and some solutions for possible cost calculations are proposed. The points of the checklist are divided in fundamental, technical and economical criteria. The evaluation of the fundamental criteria comprise the common relations, for instance customer-supplier-relations and the relations to the superior parent company. The technical criteria are related to available technologies, limits for technical feasibility, economical lot sizes and experiences with similar parts. Economical criteria verify the reliability of the customer, required price proposals of the customer etc.

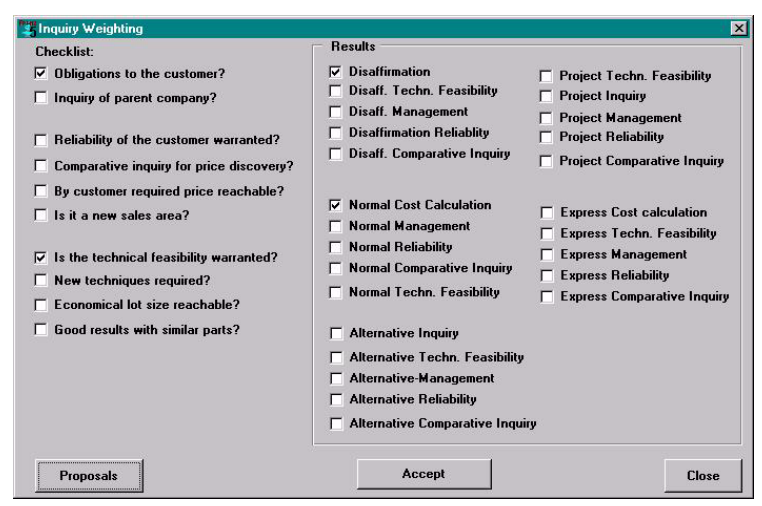

Fig.4: Weighting of Inquiries in Foundries 
Dependend on the results of the test, the program give possible kinds of cost calculations (fig. 4). This are rough calculation, normal calculation, project calculation, alternative offers and disaffirmation. Some proposals of the program have supplements, so that in some cases the agreement of the management is required. Dependent on the result the next worksteps are executed. The program based on rules which are subdivided in superior and normal rules. An example for a superior rule is "Is it a comparative inquiry THEN create a rough calculation ". The rules are represented as decision tables. Tab. 1 shows an example. There are 2 rules and 4 alternative decisions. The complete checklist comprehends 10 criteria. The consideration of all rule-combinations leads to $2^{10}$ possibilities. But not all rulecombinations are expedient and redundancies are possible.

Tab. 1: Decision Table (Y-condition filled, Ncondition not filled, $\mathrm{X}$-action part will be executed)

\begin{tabular}{|c||l|c|c|c|c||}
\hline & & R & R & R & R \\
\hline \hline B & Technical Feasibility & Y & N & Y & N \\
\hline \hline B & Comparison Inquiry & Y & Y & N & N \\
\hline \hline A & Quick Calculation & X & & & \\
\hline \hline A & Normal Calculation & & & X & \\
\hline \hline A & Alternative Offer & & & & X \\
\hline \hline A & Rejection & & X & & \\
\hline
\end{tabular}

One part of the Research Group "Workbench for Information Fusion" comprises also analyses about involvement of the results. That means, the results of the rule evaluation will be considered in furthermore weightings of future inquiries.

In exceptional case the documentation of the available equipment and conditions of use are utilized. In order to develop a software for check the technical feasibility the analysis comprehends the structure of the equipment, the flow path of castings through the single production units of the foundry, and the influence coefficients to choose from the equipment. Because of these facts the following statements are mentioned:

- Each company posses of a special structure of equipment oriented on type and number of the equipments. Very often there are several technological equipments (e.g. melting furnaces) for the same technological tasks (e.g. melting), which differ from each other in respect of capacitive and qualitative aspects.

- There is a special flow path through the foundry which depends on several constraints. Dependent on the forced-path the equipment is to choose.
- There are numerous influence coefficients, which restrict the choosing of the equipment. That are technical criteria (e.g. melting tools for special materials), organizational criteria (e.g. delivery date and available capacities), and economical criteria (e.g. piece number and quantity).

- A complete overview about the available equipment in the company and the differenciated conditions of use must be exist.

Within the scope of the investigations all substantially influence coefficients for the technical feasibility was identified. Based on these facts a database was designed with the goal to make analyses which are oriented on the decision process for the equipment. Information about conditions of use depend on the influence coefficients are evaluated, too. It is possible to insert new data or to delete data of old equipments which are sorted out. As a result of the elaborated algorithm the available equipments are showed which can used for producing a special casting. The result depends on casting characteristics.

\section{Computer-aided Generation of Raw Products}

A foundry generate a raw product if no documents for similar or equal castings are available and the volume of trade is large. The generation of the raw product contains a scheme of allocation of sheets and the draft of the raw casting (e.g. 3D-Data). The goal is an exact predefinition of manufacturing costs $[9$, 10]. This contains a derivation of points, like position, number and shape of joint lines, of cores, and of the gating and feeding systems, allowances and drafts.

In contrast to ancillary foundry industry for motor industry, which use computer-aided construction (CAD-Systems, like CATIA, ProEngineer, UNIGRAPHIX, etc.), the small foundries work with a manual generation of raw products which based on expert knowledge, like standards, guideline principles, and some other methods and equations for determining of gating and feeding. Most expert knowledge oriented on the singularity of the foundry is normally not documented. The results of the researches shall support the small foundries with help of a partially realized solution. In preparation the algorithm for generation of raw products all necessary molding processes and the particularities are analyzed. Automated molding processes have many constraints, e.g. default mold joints of the molding boxes (horizontal, vertical) and the defined dimensions. In contrast to the automated molding process the manual molding process has nearly no limits. At the use of different casting alloys, e.g. cast 
iron and cast steel, the gating and feeding of the casting is to consider. Other than the demarcation of the molding processes another task was the analysis of possible theoretical schemes of allocation of sheets. Dependent on the approach of the employee 6 basis schemes was identified. The basis schemes are conform to the 6 views of casting. Special variants are possible, e.g. angular ram up of the casting. Because of the constraints an algorithm for a derivation of a raw product, including the position for ram up, for a Seiatsu molding maschine was developed. During the execution of the algorithm the several positions for ram up the casting are eliminated because of illegitimate encores of material (allowance, drafts, feeder) on particular casting parts. The new strategy with help of the workbench contains the use of several databases. Each process step uses special infomation of different databases.

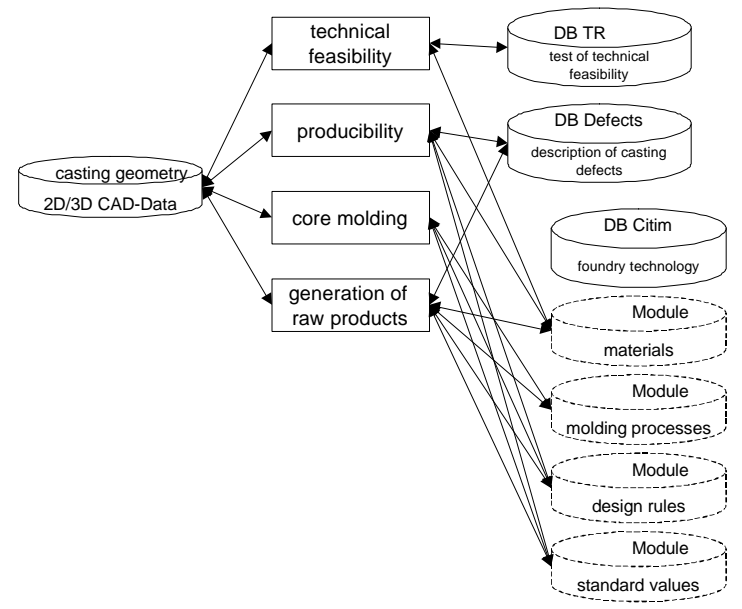

Fig. 5: Databases for Casting Design Process

With help of the databases the casting design process is supported so much as possible. Fig. 5 showes the connections between process steps and databases. It is possible that the employee needs information of several databases for one task. In order to support this, the techniques of the workbench are used. During the check of producibility an access to the databases DB Defects, DB CITIM - materials, DB CITIM - molding processes, and DB CITIM design rules is necessary. These information are filtered by the workbench. The arising new data helps the employer by the execution of the single process steps.

\section{Workflow Management and Work Scheduling}

During the process of elaborating documents for offers and manufacturing for castings a lot of different information (geometry, material, process engineering, quality, deadline) have to be considered. The data shall be effective to gather, to archive, and to systematize. Thereby a cooperation of several software systems used in foundries is necessary. Under real conditions the documents for a casting have to pass through several departments (work scheduling, construction, sale, manufacturing, ...), which are often locally separated. Different foundries use different concepts for the development of castings. That means, there are different information and documents in different foundries and very often the documents go bidirectionally between two sections. The consequence of exchanging documents multiple times is a loss of information and time. It is ascertained, that the reason for the loss of information and time are the idle periods of the documents in the single sections. In order to prevent the loss of information and time a control system (e.g. Workflow Management System) for the workout of offers is suggested.

In the phase of workout an offer in foundries a Control-System has several tasks, like control of the identified processes, management and archiving of documents of the offer (2D/3D-Data, conventional drafts, pictures, motions, ...), management of technological data (material, requirements, tasks of the casting, ...), and elaboration of post calculations (used for offers of similar or equal parts). The reduction of product development times, the reaction on the increasing product variety, a better quality of the products, and the adherence to a time limit (e.g. date of delivery) are requirements for the Workflow Management Systems. These points are conform with the requirements of the foundry. The use of modern workflow technology has several advantages. The employees are disburded by routine work and so the productivity increases and the pass-through times and the costs decrease. An improvement of quality is possible through an integration of services and quality-saving measures. A flexible reaction on desires of the customers and an effective monitoring of the sequences can be obtained, in order to analyze and solve problems very quickly with the goal to increase the satisfaction of the customer. The important decision processes in a company are accelarated. The reasons are the availability of the current data, the optimized or reorganized process sequences of the company, and the use of an automated control.

The base for the development of a control is a metamodell, which describe all necessary data. In the application field "Casting Technology" exist two kinds of sequences. There are pre-modelled sequences, which are offered by the system. That means, these pre-defined sequences contains activities which are repeated executed during the 
casting design process. A sequence, a pre-modelled sequence too, consist of processes. A process can be a sequence again or a process step. A process step is the smallest atomar unit which can be assigned to an activity. It is also possible to assign a refined process sequence instead an activity [11]. Figure 6 showes the metamodell.

The Workflow Management in the application field distinguish two layers, the technical/technological and the information technological layer. The technical layer is used in order to model processes and sequences of the application field. The information technical layer consist of activities for information technical view.

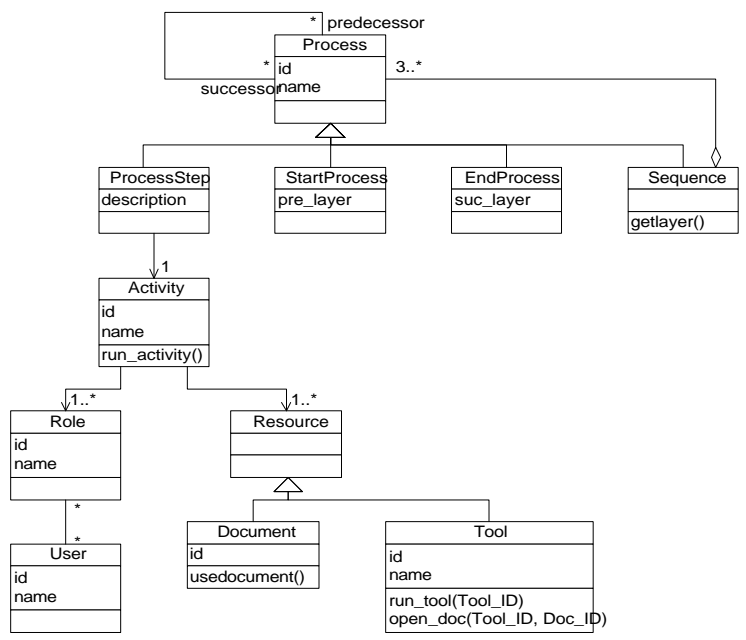

Figure 6: Metamodell for Sequences

A control system, which support especially the application field "Casting Technology" is developed. Based on this control system the techniques of the workbench are used. These concepts and techniques are assigned to special processes and offered for instance as activities.

\section{Conclusion}

A multitude of analyses regarding efficient design of the workout of offers are executed. The aim is the reduction of the process time by increased quality. Some selected work steps of the workout of offers were profoundly analyzed. Contents of future works would be check the generality of the results in comparable companies. The paper contains an overview of several developed auxiliary means for the application field "Casting Technology" and is to understand as a case study. Furthermore works comprehends the development of methods and techniques, in order to support the Information Fusion from application side.

\section{References}

[1] Sirilertworakul, N.; Webster, P.; Dean, T.A.: A software package for the design and production of castings. 60. Gießerei-Weltkongreß, The Hague 1993.

[2] Schmidt, D.; Law, T.: The benefits of PC-based solidification modelling of castings. Foundry Trade Journal, Band 167 (1993) H. 3479, p. 406 - 408.

[3] Ambos, E.; Richter, U.; Soethe, M.; Salm, Th.: Computer Aided Construction and Production of Models and Forms. Giesserei 79 (1992) 10, p. 395 - 401. (in german)

[4] Grabowski, H.: Search System for Informationfinding. VDI-Berichte Nr. 13 (647), 1987. (in german)

[5] Krötzsch, S.; Hofmann, I:Process Control in the Work Scheduling. $2^{\text {nd }}$ ICSC Symposium on Engineering of Intelligent Systems, Paisley, Scotlangd, 27.-30.06. 200

[6] Ambos, E.; Brahmann, M.; du Maire, E.; Helm, B.: Multimedia and Data Communication for Accerelation and Qualification of the Development and Production Process for Castings. Giesserei 84 (1997) 19, p. 27 - 31. (in german)

[7] Mucksch, H.; Behme, W.: The Data-WarehouseConcept. Gabler Verlag, Wiesbaden 1998. (in german)

[8] Krötzsch, S.: Workout of Offers in Foundries with Help of a Structure Dependent Control. Disseration (eingereicht April 2001), Otto-vonGuericke-Universität Magdeburg, 2001. (in german)

[9] Scheler, R.; Hofmann, I.; Krötzsch, S; Ambos, E.; Pfisterer W.: Computer Aided Search of Similar Castings for the Workout of Offers. Giesserei, 87 (2000) 8, p. 72 - 78. (in german)

[10] Hofmann, I; Krötzsch, S.; Scheler, R.; Ambos, E.; Miersch, N.; Pfisterer, W.: Effectivity through the Insert of Computer Aided Solutions in the Work Scheduling. Giesserei, 87 (2000) 10, p. 39 - 45. (in german)

[11] Scholz-Reiter, B.; Stahlmann, H.-D.; Nethe, A.: Process Modelling. Springer Verlag, 1999.

[12] Gruhn, V.: Validation and Verification of Software Process Models. Dissertation, Universität Dortmund, 1991.

[13] S. Krötzsch, I. Hofmann, G. Paul: Using of Process Modelling in the Work Scheduling. 12th International Conference on Computer Applications in Industry and Engineering (CAINE-99), Atlanta, Georgia USA, November 4-6, 1999. 